\title{
South Africa's scientists honoured as global lifesavers
}

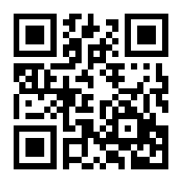

Last October, a rejuvenated, financially healthier and better-led Medical Research Council (MRC) gave lifetime achievement awards to two local scientists whose applied research has saved tens of thousands of lives in South Africa (SA) and multiples more in other countries, winning international recognition.

They are Prof. Shabir Madhi, Executive Director of the National Institute of Communicable Diseases (NICD) and Prof. Eric Bateman, founder and director of the University of Cape Town (UCT) Lung Institute. Madhi headed a team that developed and promoted pneumococcal conjugate and rotavirus vaccines, resulting in the SA government pioneering a major public immunisation campaign from 2009 onwards. The programme is now World
Health Organization-approved for routine use in developing countries, and is expected to annually save the lives of $6000-7000$ SA children alone, especially in communities with limited access to curative hospital care. Madhi's work has been particularly relevant to sub-Saharan African countries with their high burden of HIV infection. He has established himself as the leading researcher on the effect of childhood HIV on the epidemiology of pneumonia and the safety, immunogenicity and efficacy of vaccines for this vulnerable population. $\mathrm{He}$ was listed among the ' 100 World Class South Africans' in the City Press in April, ${ }^{[1]}$ a list that included presidents Nelson Mandela and Thabo Mbeki. Madhi described what he did as 'very much under the radar in the context of SA's major challenges of HIV and TB'.

\section{Pneumonia and diarrhoeal diseases kill more kids than HIV/ AIDS}

However, he added, these two diseases presented a 'biased' pattern of what children were actually dying of globally and in SA. He pointed out that HIV is no longer the leading cause of under-five mortality in SA, mainly due to increasingly effective prevention of mother-to-child transmission programmes. Figures had dropped from 69/1 000 to $47 / 1000$ currently and were expected to drop to $35 / 1000$ 'within another few years'. Madhi told a gathering of eminent SA scientists at the MRC's Tygerberg headquarters on the 30 October that that the leading cause of death globally in children between one and five years old was currently pneumonia (1.3 million annually) and diarrhoeal disease 
(700 000 annually), with half of these deaths on the African continent - despite African children making up a fraction of the global population. He described himself as an 'accidental tourist,' having been offered a job in the clinical development of vaccines just as he completed his registrarship. He added that pneumococcal conjugate vaccines, first piloted by SA's mining houses, reduced under-five mortality by $16 \%$, with rural children most likely to benefit. Rotavirus was responsible for 450000 child deaths globally every year, half in Africa. Madhi praised the National Department of Health $(\mathrm{NDoH})$ for boosting local vaccine funding from R200 million in 2009 to R1.2 billion currently. 'The net gain is that weve reduced the all-cause under-five mortality rate by $12-15 \%$. I've been fortunate to be in the right place at the right time, with the right funding and a research unit staff of some 200 people.'

\section{Tribute to Sowetan parents}

He singled out the residents of Soweto for making his unit's ground-breaking field trials possible. 'There are very few places in the world where you'll find parents willing to take on the risk of having their kids participate - based purely on the notion that it will benefit other kids in a future generation - the award is as much to them as it is to me', he added.

\section{Practical approach to lung health boosts disease detection rates}

Prof. Bateman founded the UCT Lung Institute as a strategic response to lung health and HIV-related lung problems 15 years ago and developed global guidelines for asthma treatment and chronic obstructive lung disease. He began what became known as the UCT Lung Institute's 'Knowledge Translation Unit', translating research into clinically applied solutions on the ground. Its flagship project was Practical Approach to Lung Health and HIV/AIDS in South Africa (PALSA PLUS) rolled out in partnership with the Free State Department of Health. It proved ground-breaking, initially as an on-site training course equipping nurses to diagnose and manage respiratory diseases, later adding HIV/AIDS and sexually transmitted infections (the 'PLUS') in resource-poor settings. The programme, which he said had evolved into a 'Primary Care 101', has boosted disease detection rates by between $70 \%$ and $80 \%$ and is currently being rolled out nationwide.

Bateman said the focus was on empowering front-line clinicians, improving the quality

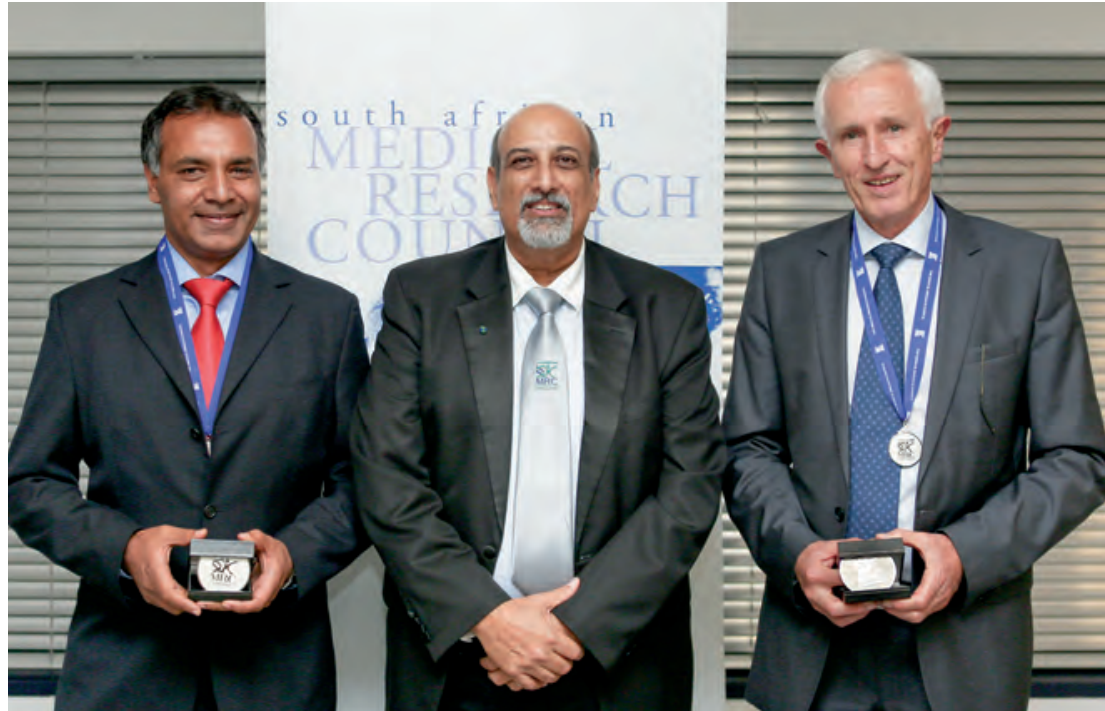

Outgoing MRC President Prof. Salim Abdool Karim (centre) with LifeTime Achievement scientists, Prof. Shabir Madhi, Director of the National Institute of Communicable Diseases (left), and Prof. Eric Bateman, founder and director of the University of Cape Town Lung Institute (right).

of care and helping build the foundations for the National Health Insurance (NHI) initiative. He said several students of his were now leaders in their fields, adding that he was proud of having developed one of the few integrated programmes with a scientific basis. Their work was showcased in Doha last November and has been rolled out as programmes in Malawi, Botswana, Mexico and Gabon. Now retired as the director of the Lung Institute, Bateman said he was looking forward to working in other underserved and poorly resourced countries and continuing with innovative research into new TB drugs. The institute, which directly employs some 70 people, also has a highly specialised laboratory for allergies and diagnostics tailored to SA diseases.

\section{MRC 'revitalised' - \\ Karim and Mazwai}

Outgoing MRC President, Prof. Salim Abdool Karim, appealed to Dr Aaron Motsoaledi, National Minister of Health (sitting beside him), to increase to $2 \%$ the research allocation in the annual health budget, saying SA had traditionally 'punched well above our weight division'. Over the past 18 months, a poorly managed (and administratively bloated) MRC had been 'turned around', receiving a clean audit, overhauling and improving its peer review mechanisms and lobbying Treasury, philanthropists and the corporate sector to raise an additional R700 million over and above the R1 billion government allocation for spending over the next three years. Intramural and extramural MRC funding had been equalised after discussions with medical schools revealed that even their best scientists running flagship projects were severely under-resourced. Having 'radically restructured' the MRC's decisionmaking processes, the new goal was 'to get money into the universities to resuscitate their best research - we don't want to take a year to turn an application around, Karim promised. He said R150 million, spread over three years, had been granted to 12 projects at universities around the country while five MRC intramural projects would receive R40 million over the same period. All these flagship projects would address the health priorities of the nation. The MRC had received 29 applications for flagship projects from 18 universities, all undergoing rigorous international peerreview, which led to $41 \%$ being successful. Large projects received about R16 million and 'moderately large' projects, R8 million. The research embraced HIV, TB, malaria, burden of disease, cardiovascular and metabolic disease, alcohol and drug abuse, and women's health.

Outgoing MRC board chairman, Prof. Lizo Mazwai, recalled being faced with toyi-toying MRC workers when he first arrived and admitted: 'we did not have a strong executive management then'. The board managed the crisis and, after changing the leadership structure, reverted to a more traditional role, leaving it to a head-hunted Karim to restore functionality. Motsoaledi said the dramatic turnaround would give the MRC more leverage for an increased Treasury allocation and expressed empathy as the political leader 
of the NDoH. 'Treasury thought we were mad when we first doubled the HIV budget, not (initially) recognising that it should have been done years ago,' he revealed.

\section{Public Healthcare Enhancement Fund}

Motsoaledi said it was vital to increase research capacity because of Africa's high burden of disease (and SA's position as the continent's economic powerhouse), while the impending NHI would need world-class scientists to help it chart the way forward and stay the course. Three years ago he had called 16 corporate executives in the private healthcare sector together in a bid to bury the hatchet and 'find things common to us all and which benefit us all. He asked them to partner with his department in combating the HIV/AIDS and TB epidemics and building a viable human resources base. This led to the R40 million Public Health Enhancement Fund, which will spend R10 million backing young scientists to complete their Masters and $\mathrm{PhD}$ degrees. To increase volume in the 'feeder pipeline', 100 specially selected aspirant doctors would be sponsored R200 000 each (across the country's eight medical schools) - with an emphasis on those from previously disadvantaged backgrounds whose university scores would have excluded them as candidates. Motsoaledi said the current teaching platform was untenable, with the last medical school built 28 years ago. He and his Higher Education counterpart were 'pushing strongly' to have a medical faculty attached to the proposed Mpumalanga University and had, in November last year, gazetted a council for a 'totally new university' that would incorporate Medunsa. 'We also want another university in the Northern Cape, with a medical faculty' he revealed.

The current total annual SA-trained doctor production is 1200 for a population of 51 million, the doubling of which, on the government's best advice, will take 15 years just to maintain the current doctor-population ratio. The other shortterm human resources crisis intervention is the sending of the first batch of 1000 medical students to Cuba for training this year, while universities engage government and the Health Professions Council of SA on expanding existing training platforms while retaining output quality. Another R10 million of the Fund will be ploughed into the still-conceptual Academy for Leadership and Management in Health Care.

\section{Chris Bateman}

chrisb@hmpg.co.za

1. 100 World Class South Africans: Shabir Madhi. City Press, 13 August 2013. http://www.citypress.co.za/lifestyle/100-worldclass-south-africans-shabir-madhi/ (accessed 13 November 2013).

S Afr Med J 2013;103(12):890-892.

DOI:10.7196/SAMJ.7718 